\title{
First records of the antlion genus Solter Navás from southern Africa, with description of a new species (Neuroptera: Myrmeleontidae: Myrmecaelurini)
}

\author{
MERVYN W. MANSELL
}

Department of Zoology and Entomology, University of Pretoria, Pretoria 0002, South Africa. E-mail:mansel@mweb.co.za

\begin{abstract}
A new species of Solter Navás is described from South Africa, representing the first record of this genus from Africa south of the equator. The new species provides a significant extension to the known distribution range of this predominantly Palaearctic genus. The species described here is characteristically reddish brown with a banded abdomen, and was recorded at three localities in arid rocky areas in the Northern Cape Province of South Africa.
\end{abstract}

Key words: Neuroptera, Myrmeleontidae, Myrmecaelurini, Solter, new species, South Africa, Afrotropical Region

\section{Introduction}

Solter Navás, 1912 is essentially a genus of the Palaearctic Region, occurring mainly in the Middle East and Saudi Arabia (Stange 2004). The genus comprises 28 species and extends from Morocco and Portugal in the west, eastwards to Afghanistan, Pakistan and India and southwards into the northern Afrotropical Region to Sudan, Niger, Somalia and Socotra Island (Stange 2004). Four species, S. dubiosus Hölzel, 1981, S. liber Navás, 1912, S. propheticus Hölzel, 1981, and S. virgilli Navás, 1931, were hitherto known from Afrotropical Africa.

Solter species had not been recorded from south of the equator until a series of specimens that can clearly be assigned to this genus was identified from South Africa. These records represent a significant southern extension of the known range of Solter and a unique addition to the South African antlion fauna. The specimens were attracted to light and hand-netted in arid rocky areas of the Northern Cape Province. Known larvae have been found under protected rock overhangs in deserts (Stange 2004), but the larva of the South African species remains unknown.

The following abbreviations are used in the text: A1 - A3, anal veins; $\mathrm{CuA}$, anterior cubital vein; $\mathrm{CuP}$, posterior cubital vein; MP2, second branch of posterior median vein; Rs, radial sector, TA1 - TA5, tarsomeres 1-5; SANC, South African National Collection of Insects. 
monotypy.

Sartous Navás, 1914: 207; Stange 2004: 279.

Nelus Navás, 1929: 44; Hölzel 1972: 33.

\section{Diagnosis}

Robust medium-sized antlions with short clavate antennae; forewings with $\mathrm{CuP}$ arising close to basal crossvein, 2A extends in an even curve towards $3 \mathrm{~A}$; hind wings with 3 or more presectoral crossveins; males with pilula axillaris, femoral sense hairs present on fore and middle femora, absent from hind femora; tarsomere 5 longer than tarsomeres 1-4 combined; tibial spurs stout, curved, extending beyond tarsomere 1.

\section{Solter san sp. nov. Figs $1-8$.}

Etymology: San, a noun in apposition, the name of the original human inhabitants of southern Africa after whom the area known as "Bushmanland" is named: this encompasses the distribution range of the new species.

\section{Description}

Habitus (Fig. 1). Distinctly reddish-brown medium-sized antlions with short clavate antennae. Abdomen characteristically banded with pale and dark reddish-brown. Wings long, fairly narrow, with alternating pale and light brown markings on wing veins. Legs with stout curved tibial spurs and preapical claws.

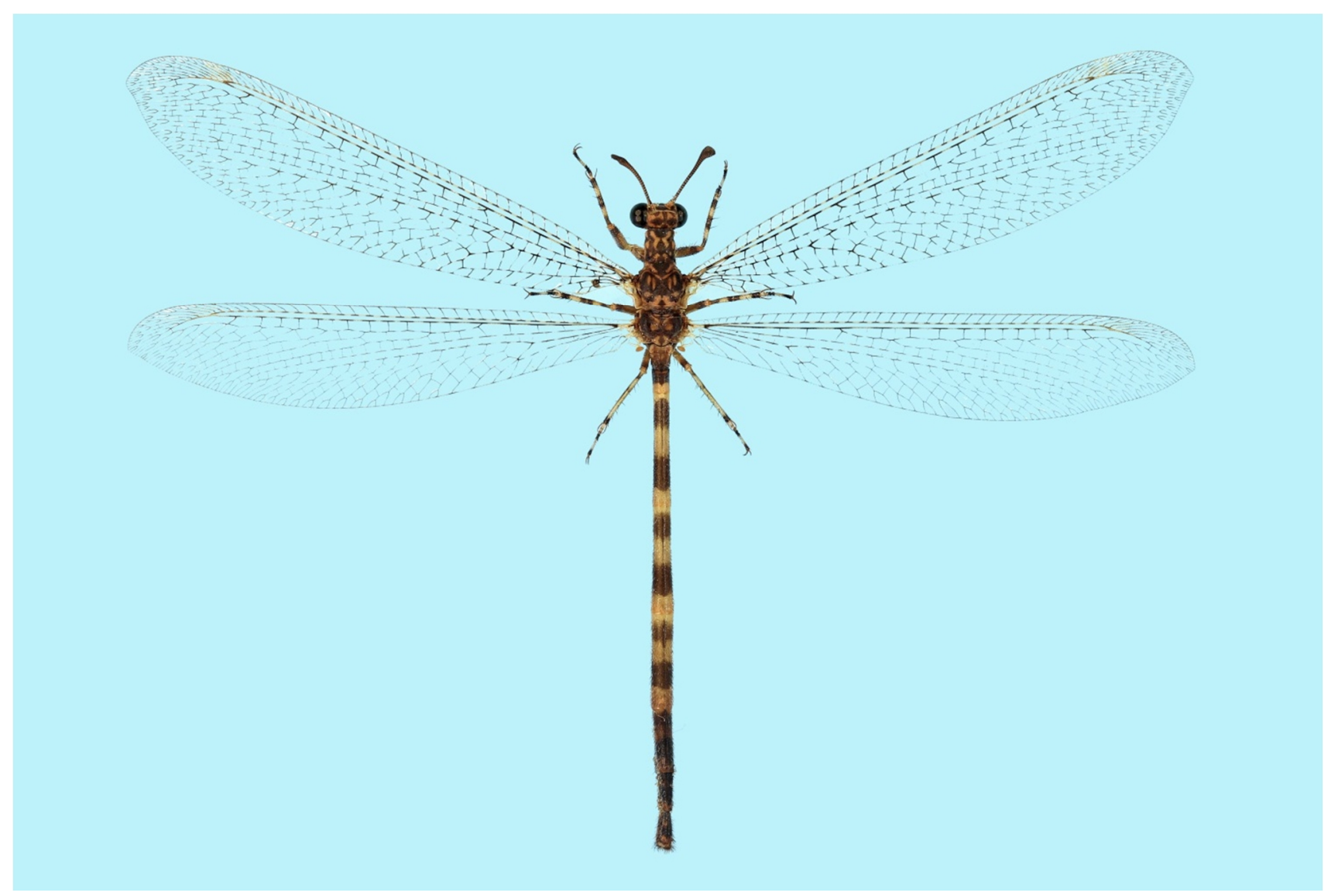

Fig. 1. Solter san sp. nov. Male holotype, Kenhardt, South Africa. Photo: L.P. Snyman 


\begin{tabular}{|c|c|c|c|c|c|}
\hline mm & $\begin{array}{c}\text { Antenna } \\
\text { length }\end{array}$ & Head width & $\begin{array}{c}\text { Forewing } \\
\text { length }\end{array}$ & $\begin{array}{c}\text { Hind wing } \\
\text { length }\end{array}$ & Body length \\
\hline \hline $\begin{array}{c}\text { Holotype } \\
\text { Male }\end{array}$ & 4.6 & 3.6 & 34.7 & 32.0 & 38.6 \\
\hline Paratypes & 4.1 & 3.3 & 31.1 & 29.1 & 35.8 \\
Male (18) & $3.5-4.7$ & $2.9-3.9$ & $26.0-36.6$ & $24.7-34.3$ & $30.5-41.8$ \\
\hline \hline Paratypes & 4.4 & 3.6 & 33.3 & 31.4 & 33.2 \\
Female (11) & $3.8-5.3$ & $3.2-4.1$ & $30.7-37.0$ & $28.9-34.4$ & $30.8-37.4$ \\
\hline
\end{tabular}

Head: wider than prothorax, vertex raised, rounded; antennae short, clavate, slightly longer than head width, toruli greater than scape width apart set in deep recess, scape pale, flagellomeres short, uniformly brown, covered with very short black setae; eyes large, greater than hemispherical, ocular setae absent; maxillary and labial palps short, much less than head width, pale yellow, terminal labial palpomere spindle-shaped with acute apex, palpimacula round (Fig. 3). Vertex brown with 4 pale diffuse spots, a large brown mark centrally on occiput, frons pale below vertex, with a brown band overlying toruli; clypeus, genae, labrum pale.

Thorax: prothorax narrow, longer than wide, with sparse long white setae laterally, short black setae centrally, long curved black setae along posterior margin. Pronotum dark brown with pale markings: a pair of curved pale marks anteriorly, two at posterior margin, two pale spots laterad of these, with a pale streak on each lateral margin. Meso- and metathorax sparsely haired, only with sparse white setae posteriorly on each segment; mesoprescutum dark brown with pale margins, mesoscutum dark brown with two pale streaks on either side of midline, mesoscutellum pale with dark anterior-lateral margins and dark central streak; metascutum dark brown with pale spot on either side of midline, metascutellum pale with dark antero-lateral margins and dark central streak.

Wings: long, narrow; forewings slightly longer than hind wings, apices sub-acute, membrane hyaline, veins with alternating bands of pale and light-brown, bearing very short sparse black setae, costal area uniaereolate, hypostigmatic cells long, hind margins smooth. Forewings with 4-5 presectoral crossveins, Rs arising beyond $\mathrm{CuA}$ fork, MP2 (oblique vein) arising beyond $\mathrm{CuA}$ fork, $\mathrm{CuP}$ arises at same level as basal crossvein, fused with $1 \mathrm{~A}$ after a short free base, A2 not parallel to A1, evenly curved, pterostigma small, pale pink. Hind wings with 2-3, occasionally 4 presectoral crossveins, Rs arises beyond MP2 fork, CuP fused with 1A, pterostigma hardly discernible, pilula axillaris present in males.

Legs (Fig. 2) longish, hind legs longer and more slender than fore and middle legs, tarsi much shorter than tibia in all legs, TA1 - 4 shorter than TA5, TA1 short, less than TA2 - 4, tibial spurs robust, pale brown, evenly curved, extending beyond TA2 in all legs, TA5 long, preapical claws robust, pale brown, evenly curved, sparse black setae along entire ventral surface of tibia, femoral sense hairs present on fore and middle legs, absent from hind legs. Foreleg with robust curved white and black setae ventrally, tibia with sparse long black setae laterally, femur with dark apices, tibia pale with dark band proximally, double band 
medially, apices dark, TA1 and TA2 pale yellowish, TA3 and TA4 dark brown, TA5 pale with dark apices, middle leg coloration similar to foreleg, hind legs with pale tibiae with dark apices, coloration of tarsi as in other legs.

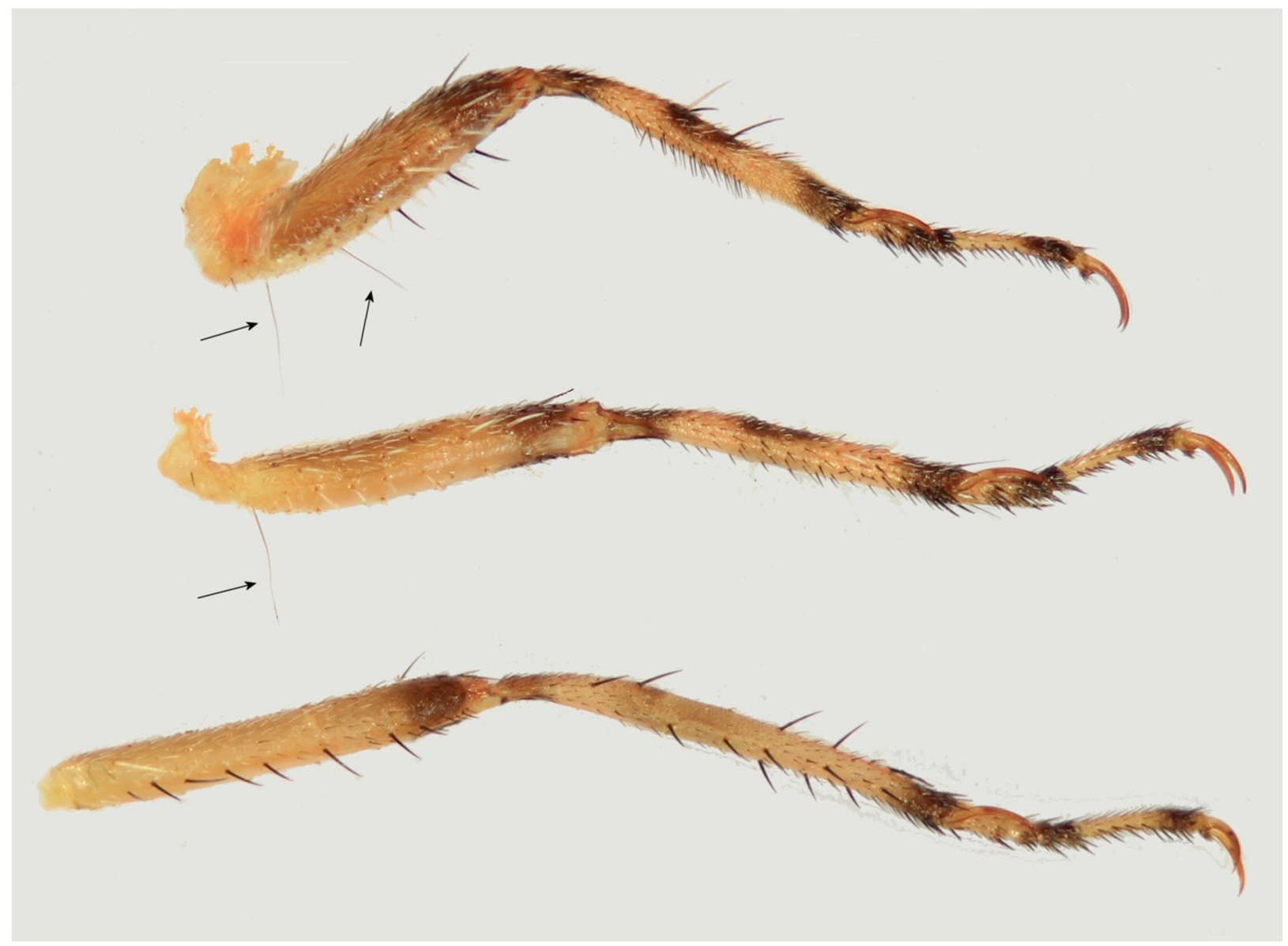

Fig. 2. Solter san sp. nov. Fore, mid and hind legs, showing femoral sense hairs on fore and middle legs. Photo: L.P. Snyman.

Abdomen: with alternating pale and dark reddish-brown bands, T1 with long curved white setae dorsally, remainder of abdomen with short sparse white and black setae, becoming longer on T7 - T9.

Male genitalia (Figs 4-6): with short ectoprocts lacking postventral lobes or extensions; sternite 9 large with subacute rounded apex. Internal genitalia tiny, parameres capsule-shaped in caudal (posterior) view with two horn-like flanges dorso-laterally; mediuncus distinct, wide, with densely arranged minute punctations on dorsal surface.

Female genitalia (Figs 7, 8): anterior gonapophyses slender, elongated covered with long slender setae; posterior gonapophyses short, stout, articulating with bases of lateral gonapophyses, covered in short, stout black setae; lateral gonapophyses long with very stout black fossorial setae.

Larva unknown.

\section{Material examined}

SOUTH AFRICA, Northern Cape Province: Holotype đ̊̄, NEUR08954, Driekop Nature Reserve, Kenhardt, 2923'S $21^{\circ} 06^{\prime} \mathrm{E}, 850 \mathrm{~m}$, 24.ii.1996, M.W.Mansell, H.\&U.Aspöck, H.Hölzel, P.Ohm, at light. Paratypes: 
$3 \hat{\jmath}$, NEUR08953, same locality as holotype,19.ii.1991, M.W.Mansell, C.D.Eardley, at light; $13 \hat{\jmath}, 8 \circ$, NEUR08954, same data as holotype; $3{ }^{\lambda}$, 2 ㅇ, NEUR08955, Uurhoogte $11 \mathrm{~km}$ E Fraserburg, 31 ${ }^{\circ} 50^{\prime} 56^{\prime \prime} \mathrm{S}$ 2135'59’'E, 1266m, 16.ii.1996, M.W.Mansell, H.\&U.Aspöck, H.Hölzel, P.Ohm, at light; 19, NEUR08956, Pofadder Commonage, 2905'58’S 19²4'22’'E, 1016m, 25.ii.1996, M.W.Mansell, H.\& U.Aspöck, H.Hölzel, P.Ohm, at light.

\section{Acknowledgements}

I thank L.P. Snyman (University of Pretoria) for the photographs. C.D. Eardley (SANC), H. Aspöck, U. Aspock (University of Vienna), and the late H. Hölzel (Bruckl, Austria) and P. Ohm (Kiel, Germany) are thanked and acknowledged for participation in the field trips that led to the discovery of this new species. The Northern Cape Department of Nature Conservation is acknowledged for granting of research permits. C.H.Scholtz and J.B.Ball are thanked for reading and commenting on the manuscript.

The JRS Foundation is sincerely acknowledged for providing a grant towards the exploration and documentation of Neuroptera biodiversity.

\section{References*}

Hölzel, H. (1972) Die Neuropteren Vorderasiens IV. Myrmeleonidae. Beiträge zur Naturkundlichen Forschung in Südwestdeutschland, 1, 3-103. 2968*.

Hölzel, H. (1981) Notes on ant-lions (Neuroptera: Myrmeleonidae) of Israel and adjacent countries, with descriptions of new species. Israel Journal of Entomology, 14, 29-46. 2987.

Navás, L. (1912) Notas sobre Mirmeleónidos (Ins. Neur.). Brotéria (Zoológica), 10, 29-75, 85-97. 0555.

Navás, L. (1914) Neurópteros de la Tripolitania. II serie. Annali del Museo Civico di Storia Naturale Giacomo Doria, Genoa, 46, 202-209. 0608.

Navás, L. (1929) [Insecta orientalia.] VII Series. Memorie dell'Accademia Pontifica dei Nuovi Lincei, Rome, (2) $12,43-56.0852$.

Navás, L. (1931) Insectos de Somalia y Eritrea (Africa). Boletín de la Sociedad Entomologica de España, 13, 130-137. 0901.

Stange, L.A. (2004) A systematic catalog, bibliography and classification of the world antlions (Insecta: Neuroptera: Myrmeleontidae). Memoirs of the American Entomological Institute, 74, 1-565. 11168.

*The numbers in bold after each reference correspond to the universal numbering system of Neuropterida literature in the Lacewing Digital Library portal: http://lacewing.tamu.edu/LDL/indexcontent.html. Chief Editor: John D. Oswald, Texas A \& M University

\section{LEGENDS TO FIGURES}

Figs 3-8. 3, Labial palpi, male and female; 4, Male terminalia, lateral; 5, Male genitalia, caudal (posterior) view; 6, Male genitalia, dorsal view; 7, Female terminalia, lateral view; 8, Female terminalia, ventral view' Abbreviations: Epr, Ectoproct; G, Gonarcus; Ga, Anterior gonapophyses; Gl, Lateral gonapophyses; Gp, Posterior gonapophyses; Pa, Paramere; Pm, Palpimacula; S9, Sternite 9; T9, Tergite 9 . 

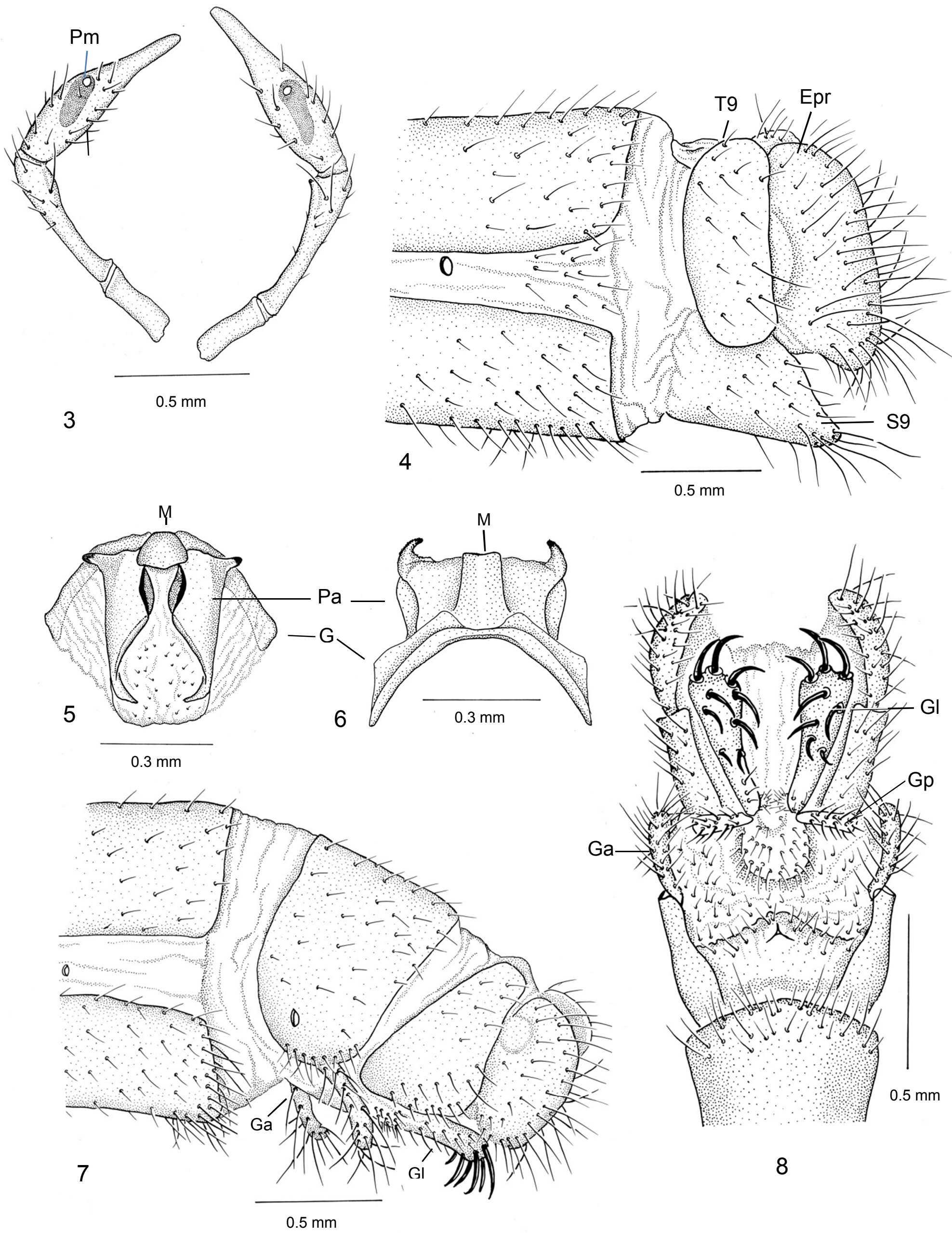